\title{
Utilization of Agricultural Wastes in Stabilization of Landfill Soil
}

\author{
Mohamad Nidzam Rahmat ${ }^{1}$, Muhammad Redzwan Raffe ${ }^{2}$, Norsalisma Ismail $^{3}$ \\ ${ }^{1,2,3}$ Faculty of Architecture, Planning and Surveying, Universiti Teknologi MARA, 40450 Shah Alam. \\ Selangor. Malaysia.
}

\begin{abstract}
Palm Oil Fuel Ash (POFA) and Rice Husk Ash (RHA) are local agricultural waste material from Palm Oil Industry and from Paddy Industry in Malaysia. Currently, the disposal of these ashes from a burning process is a problem to both industries, and hence leads to environmental pollution. The main aim of this research was to investigate the potential of utilizing POFA and RHA as sustainable stabilizer material as partial replacement of traditional one which is lime and Portland Cement (PC). Laboratory investigations were carried out to establish the potential utilization of Malaysian Agricultural wastes POFA and RHA in stabilizing Teluk Kapas Landfill soil. Landfill soil on its own and combination with laterite clay soil were stabilized using POFA or RHA either on its own or in combination with Lime or Portland Cement (PC). The traditional stabilizers of lime or Portland Cement (PC) were used as controls. Compacted cylinder test specimens were made at typical stabilizer contents and moist cured for up to 60 days prior to testing for compressive and water absorption tests. The results obtained showed that landfill soil combined with laterite clay (50:50) stabilized with 20\% RHA:PC (50:50) and POFA: PC (50:50) recorded the highest values of compressive strength compared to the other compositions of stabilizers and soils. However, when the amount of POFA and RHA increased in the system the compressive strength values of the samples tends to increase. These results suggest technological, economic as well as environmental advantages of using POFA and RHA and similar industrial by-products to achieve sustainable infrastructure development with near zero industrial waste.
\end{abstract}

\section{Introduction}

Traditional soil stabilization using lime or cement is well established. Although this type of stabilization is very popular and has been successful in the past, there is a need to look for other alternative technologies which are more environmentally friendly and economical. Lime is an expansive material and is difficult to work with. This is similar to the manufacture of cement which leads to environmental pollution. The $\mathrm{CO}_{2}$ emitted from the manufacturing process is the major influence on climate change due to the enhanced greenhouse effect. At present the used of lime or cement are slowly be taken by the industrial and/or agricultural waste by-product which proved sustainable and provides cost effective methods to improve the engineering properties of low loadbearing or problematic soils. Soils stabilized with industrial waste materials have been extensively tested and do not have any adverse environmental impact and consequences [1]. 
The aim of this study is to investigate the potential of using agricultural wastes Palm Oil Fuel Ash (POFA) and Rice Husk Ash (RHA) as stabilizer for soil stabilization and as partial replacement of traditional binder lime or PC. As the palm oil industry is continuously expanding in Malaysia, the production of waste from the process are also increasing especially the palm oil fuel ash (POFA), waste that generated from the burning process of empty fruit bunches, fibres and kernals. POFA are not reusable and normally dumped as waste without profitable return [2, 3]. On the other hand, Rice Husk is another agricultural by products obtained from food crop of paddy. Estimation of for every 4 tons of rice milled, 1 ton of rice husk is produced.

Burning of rice husk generates about $15-20 \%$ of its weight of ash. The normal method of conversion of husk into ash is incineration. Rice Husk Ash (RHA) being very light is easily carried by wind and water in its dry state. It is difficult to coagulate and thus contributes to air and water pollution. Additionally cumulative generation of ash requires large space for its disposal. Previous researchers found that high percentage of siliceous materials in RHA indicates it has potential pozzolanic properties. In Malaysia most of the agricultural waste ended up in landfill.

These wastes which possess pozzolanic properties have a potential to be use as an alternative to soil stabilization or concrete as traditional binder. Another serious problem faced by many municipal in Malaysia is solid waste landfill. Most of the open dumping area has no post closure maintenance would possess serious hazards to the surrounding communities due to differential settlement of the waste soil. Estimation of settlement for municipal solid waste is critical to the successful site operation and the future development.

This problem could be an opportunity to other people. Contaminated area may be restored by rebuilding a new area such as playground, football field or low-cost housing area if possible. This abandoned landfill site could be re-engineered either by mechanical or chemical stabilization techniques for redevelopment [4]. Therefore the aim of this research was to investigate the potential of POFA and RHA as stabilizer in soil stabilization as a partial replacement of traditional binder lime or PC. The objectives of this paper were to determine the potential of POFA and RHA on the stabilization of landfill soil and also to access the engineering properties of stabilized soil

\section{Experimental Procedures}

\subsection{Target Material}

Landfill soil - The landfill soil was taken at Teluk Kapas (Figure 1), a municipal solid waste landfill. It was shut down in the year of 2007 due to close to water intake points. As the solid waste discompose, it influenced the properties of the soil. The properties of surface soil at landfill area generally depend on type of waste being dumped on the landfill.

Municipal solid waste is highly heterogeneous and the composition is depends on the living standard, type of housing, seasons and country which include cultural habits of individuals [5]. Municipal solid waste includes waste from residential, commercial, institutional, and some industrial sources.
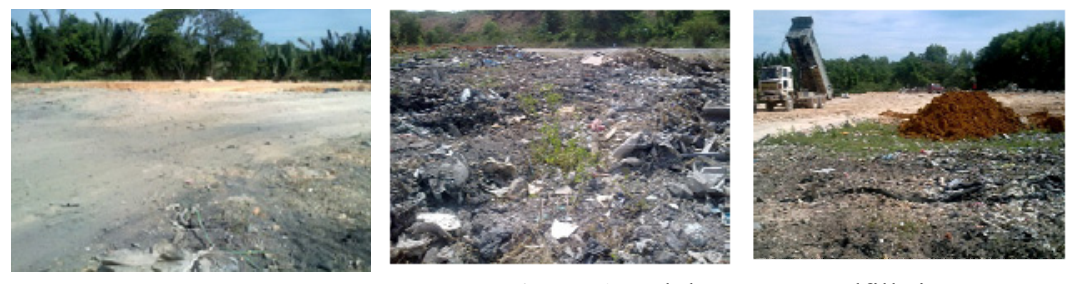

Figure 1: Teluk Kapas Landfill site

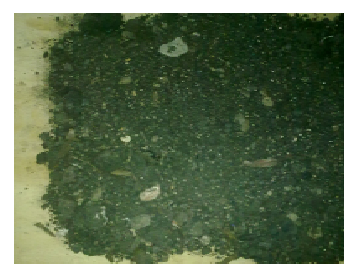


Laterite soil - is well known in Malaysia and Asian countries as a building material for more than 1000 years. It is a highly weathered material, rich in secondary oxides of iron and aluminium or both and hence its colour is reddish brown [6]. Laterite soils are formed by the rock layer breaking down which leaching soluble ingredients of soils and leaving behind clay minerals (kaolinite), gibbsite $\left(\mathrm{Al}_{2} \mathrm{O}_{3} \cdot 3 \mathrm{H} 2 \mathrm{O}\right)$, goethite $\left(\mathrm{HFeO}_{2}\right)$, lepidocrocite $(\mathrm{FeOOH})$, and hematite $\left(\mathrm{Fe}_{2} \mathrm{O}_{3}\right)$. A reddish laterite soils which rich in (hydr) oxides known as laterite clay [7]. The iron oxides present in the soil environment coated and bound the clay particles together. The properties of laterite clays generally depend on the geographical location, extent of lateralization and the chemical and physical composition of the parent rock.

\subsection{Stabilizer}

Palm Oil Fuel Ash (POFA) - Palm oil fuel ash is a by-product produced in palm oil mill. POFA generally is a product of palm oil husk and palm kernel shell which are burned as fuel in the boiler of palm oil mill [8]. Generally, after combustion about 5\% palm oil fuel ash by weight of solid wastes is produced [9]. POFA usually have varies in tone of colour based on the carbon content in it. The colour may vary from whitish grey to darker shade. Based on the previous research done [10], he found that the physical characteristic of POFA is very much influenced by the operating system of the palm oil factory.

Rice Husk Ash (RHA) - Rice is an agricultural crop that continues to be an important source of food and nutrition in Malaysia. The total area planted with paddy in Peninsular Malaysia is 454917 ha, which constitutes 61.3 percent of total paddy plantings in the country. Rice husk is an agricultural by product from rice milling. During the paddy milling, about 78 percent of weight is received as rice, broken rice and bran while the other 22 percent of the weight of paddy is received as husk. The Rice Husk Ash (RHA), which is developed from the burning of the rice husk at a certain temperature, has been used for cementing material and also has good adsorptive properties [8].

Portland cement (PC) and Lime - PC and lime were used as control stabilizers. PC had long successful history in stabilizing both granular and fine-grained soils, as well as aggregates and miscellaneous materials. A pozzolanic reaction between the calcium hydroxide released during hydration and soil alumina and soil silica occurs in fine-grained clay soils and is an important aspect of the stabilization of soils [11]. Lime is used extensively for the stabilization of soil, especially soil with a high clay content where its main advantage is in raising the plastic limit of the clayey soil. When added to clay soils, lime reacts with water in the soil and reduces the soil's water content. The oxide composition of target material and stabilizers are presented in Table 1.

Table 1: Oxide composition of Clay, POFA, PC and Lime

\begin{tabular}{|c|c|c|c|c|c|}
\hline Oxide composition & Laterite Clay & POFA & RHA & PC & Lime \\
\hline $\mathrm{CaO}$ & - & 11.30 & 2.42 & 64.64 & 74.23 \\
\hline $\mathrm{P}_{2} \mathrm{O}_{5}$ & 16.71 & - & - & - & 0.08 \\
\hline $\mathrm{MgO}$ & - & 3.55 & 1.71 & 2.06 & 0.74 \\
\hline $\mathrm{CaSO}_{4}$ & - & - & - & - & 0.12 \\
\hline $\mathrm{Fe}_{2} \mathrm{O}_{3}$ & 29.40 & 5.73 & 0.26 & 3.36 & 0.17 \\
\hline $\mathrm{Al}_{2} \mathrm{O}_{3}$ & 24.31 & - & 0.65 & 5.60 & 0.11 \\
\hline $\mathrm{SiO}_{2}$ & 21.55 & 52.50 & 82.40 & 21.28 & 0.14 \\
\hline $\mathrm{SO}_{3}$ & 3.98 & 0.82 & 0.52 & 2.14 & - \\
\hline $\mathrm{N}_{2} \mathrm{O}$ & 0.07 & - & 0.30 & 0.05 & - \\
\hline $\mathrm{CO}_{2}$ & 3.65 & 0.10 & - & - & - \\
\hline $\mathrm{LOI}$ & - & - & 10.09 & 0.64 & 24.4 \\
\hline
\end{tabular}


Table 2: Mixed composition of target material and stabilizer subjected to compressive strength test

\begin{tabular}{|c|c|c|c|c|c|}
\hline $\begin{array}{c}\text { Target } \\
\text { Material }\end{array}$ & Stabilizer & $\begin{array}{c}\text { Ratio } \\
(\%)\end{array}$ & $\begin{array}{c}\text { Dosage } \\
(\%)\end{array}$ & $\begin{array}{c}\text { Compressive } \\
\text { Strength Test }\end{array}$ & $\begin{array}{c}\text { Water } \\
\text { Absorption } \\
\text { Test }\end{array}$ \\
\hline & Lime & 100 & 20 & $\sqrt{ }$ & $\sqrt{ }$ \\
\hline & PC & 100 & 20 & $\sqrt{ }$ & $\sqrt{ }$ \\
\hline $\begin{array}{c}\text { LFs } \\
(100 \%)\end{array}$ & POFA: Lime & $50: 50$ & 20 & $\sqrt{ }$ & $\sqrt{ }$ \\
\hline & POFA:PC & $50: 50$ & 20 & $\sqrt{ }$ & $\sqrt{ }$ \\
\hline & RHA: Lime & $50: 50$ & 20 & $\sqrt{ }$ & $\sqrt{ }$ \\
\hline & RHA:PC & $50: 50$ & 20 & $\sqrt{ }$ & $\sqrt{ }$ \\
\hline & Lime & 100 & 20 & $\sqrt{ }$ & $\sqrt{ }$ \\
\hline LFs+ & POFA: Lime & $50: 50$ & 20 & $\sqrt{ }$ & $\sqrt{ }$ \\
\hline Clay & POFA:PC & $50: 50$ & 20 & $\sqrt{ }$ & $\sqrt{ }$ \\
\hline
\end{tabular}

\subsection{Specimen preparation}

For the purpose of sample preparation, it is necessary to establish the target dry density and moisture content values. Proctor compaction tests were carried out in accordance with BS 1377 (1990) Part 2, in order to establish values of the maximum dry density (MDD) and optimum moisture content (OMC) for LOC. From the test, the MDD value of $1.42 \mathrm{Mg} / \mathrm{m}^{3}$ and $\mathrm{OMC}$ value of $24 \%$ were established. Using these parameters, the bulk density of test specimens of dimensions $50 \mathrm{~mm}$ diameter and $100 \mathrm{~mm}$ in length was established. Allowing for about $10 \%$ material waste during the mixing operations, cylinder test specimens using different materials ingredients were calculated weight $380 \mathrm{~g}$, thus maintaining the same density for all test specimens irrespective of their particular mix compositions. Strength development was established as determined by the unconfined compressive strength (UCS) at the two curing ages of 7, 28 and 60 days. Three cylinders per mix proportion were subjected to unconfined compressive strength (UCS) test in accordance with BS 1924-2 and the mean strength determined.

\section{Results and Discussions}

\subsection{Unconfined Compressive Strength (UCS)}

The effect of various stabilizers on the strength characteristics of landfill soil were studied by assessing the strength development for 3 curing periods. Three samples were tested for each blended soil mixtures and the mean value taken. Figure 2 shows the effect of traditional stabilizer Portland Cement (PC) and Lime as a control on the strength development for landfill soil. The overall strength for stabilized specimens increases as the curing period increases from 7, 28 to 60 days and when percentage of stabilizer increase from $10 \%$ to $20 \%$. Generally higher dosage of lime or PC (20\%) gives higher strength value throughout 3 curing period. Stabilized landfill on its own at 60 days curing with $20 \%$ stabilizer, both PC and lime recorded almost the same strength value about $145 \mathrm{kN} / \mathrm{m}^{2}$. When landfill soil were combined with clay at 50:50 ratio mixed with PC and lime at 10\% and 20\%, the strength is higher than when landfill were stabilized alone. Again, 20\% dosage of stabilizer recorded higher strength at all curing period. Same with stabilized landfill, 60 days of curing marked highest value for both stabilizer about $340 \mathrm{kN} / \mathrm{m}^{2}$. 


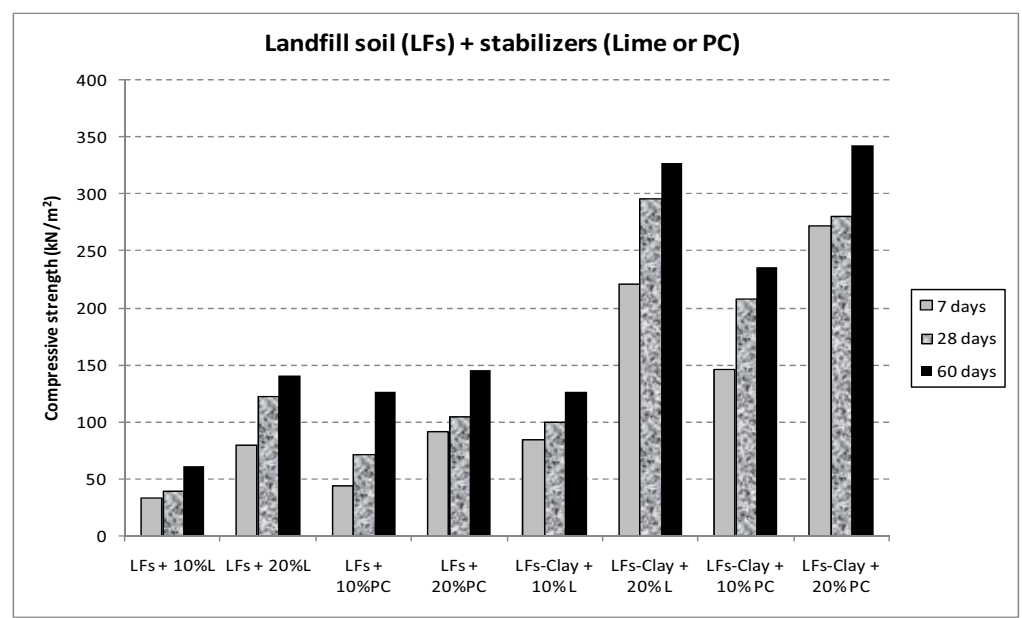

Figure 1: Compressive strength for stabilized landfill soil with Lime or PC

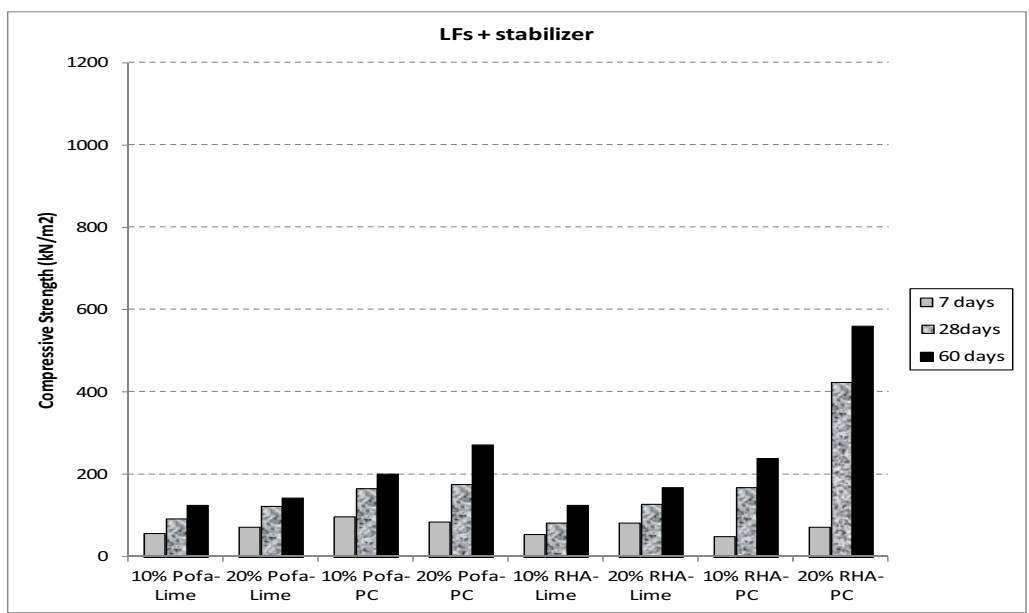

Figure 2: Compressive strength for stabilized landfill (100\%) with blended stabilizer

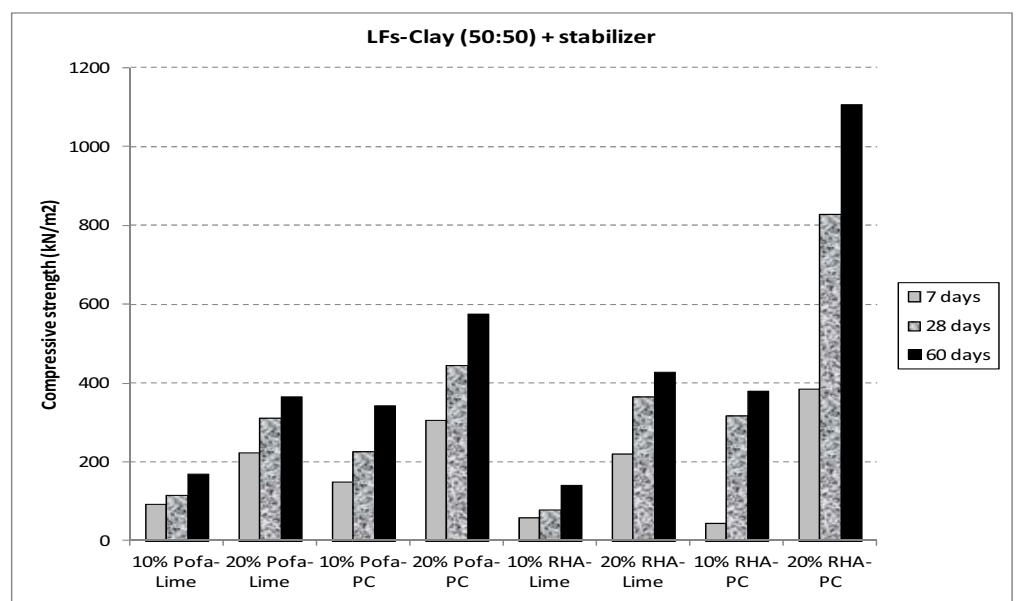

Figure 3: Compressive strength for Landfill soil + Clay (50:50) with blended stabilizer 
Figure 2 shows the strength development when landfill soil on its own were stabilized with agricultural waste POFA and RHA combined with either lime or PC at 50:50 ratio, 10\% and 20\% dosage (POFA:PC/POFA:lime and RHA:PC/RHA:lime). At 10\% stabilizer content was not sufficient to boost the strength development for both POFA-lime and POFA-PC, which recorded lower strength development compared to when $20 \%$ stabilizer was used. The combination of PC to POFA or RHA as stabilizer gives higher strength in this system to compare with when lime were used to combine with POFA or RHA. The highest strength value was recorded when landfill soil was stabilized with $20 \%$ dosage of RHA: PC at 60 days of curing which is $560 \mathrm{kN} / \mathrm{m}^{2}$. Whereas when landfill soil were stabilized with $20 \%$ dosage of POFA: PC the strength was only $270 \mathrm{kN} / \mathrm{m}^{2}$.

Figure 3 shows the effect on strength when siliceous material clay was mixed with landfill soil at 50:50 ratios. It can be seen that the strength of the stabilized specimen increased as the curing period increase. The overall strength values recorded were higher than the system without incorporating clay. As for previous system, the $20 \%$ stabilizer dosage gives higher strength development for all curing period compared to $10 \%$ stabilizer dosage. The combination of RHA: PC marked the highest strength values which is $1105 \mathrm{kN} / \mathrm{m}^{2}$ compared with POFA: PC which is $574 \mathrm{kN} / \mathrm{m}^{2}$ were recorded at 60 days of curing period. Lime did not perform well in terms of strength development when combined with either POFA or RHA.

The combination of Landfill soil and Clay gives better compressive strength values compared with when landfill soils were stabilized alone. It is proved that with adding clay which contain siliceous matter, the pozzolanic reaction and cementitious compound increased and gives better bonding between soil particles, and thought to be due to increased pozzolanicity of the system related to the system stabilized without siliceous material clay. Results from the experimental shows that the compressive strength values increases when the amount of stabilizers and curing period increased. As being proved by several researcher [12], [13] in their research, the increasing amount of cement, lime and curing time affects the values of compressive strength of stabilized soil. When PC was blended with RHA at 50:50 ratios, the strength development is continuous throughout the 60 days curing. This is perhaps because RHA contains a large amount of silica (see Table 1) which has high potential to be used as cement replacement [14]. It is generally recognized that the principal cementitious product of pozzolanic reaction is calcium-alumino-silicate-hydrate $(\mathrm{C}-\mathrm{A}-\mathrm{S}-\mathrm{H})$.

\subsection{Water Absorption}

This test was to determine the percentage of water absorb by the stabilized specimens by total immersion of the samples into the water after being cured for 28 days. Readings were taken for 8 days consecutively. Figure 4 and Figure 5 shows the percentage of water absorption of stabilized specimens. From the observation, generally in all systems the percentage of water absorption increases rapidly within the first 3 days of immersion. The rate of absorption became slow and levelled off on day 4 and onwards which is between $8 \%-10 \%$ absorption. Landfill soil on its own when stabilized with combination of lime to POFA or RHA attained lower percentage of water absorption compared to when PC were used to incorporate with the agriculture wastes. When landfill soils were combined with siliceous material clay, the absorption rate is comparable with the previous system. This system recorded that stabilized POFA-Lime at $20 \%$ absorb the highest amount of water (about 10\%) compared to other stabilized specimen. 


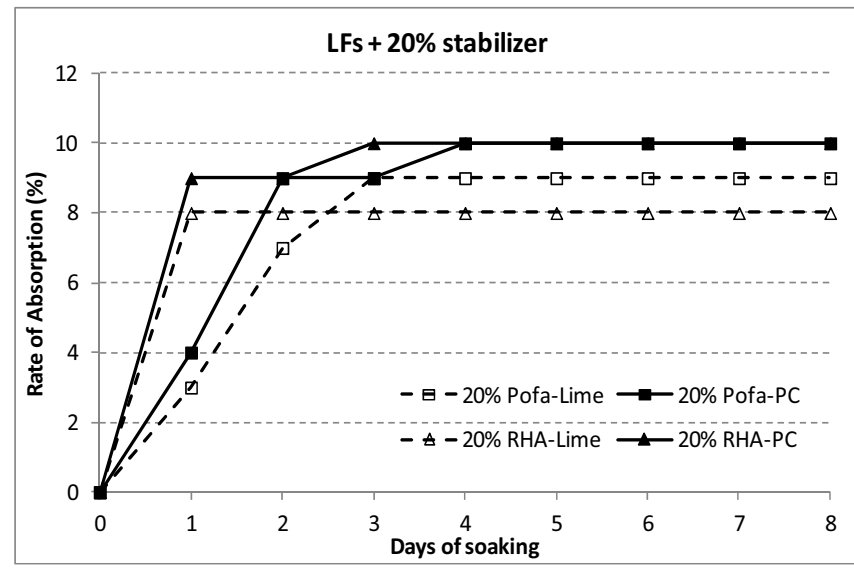

Figure 4: Rate of water absorption for stabilized landfill soil with $20 \%$ blended stabilizer

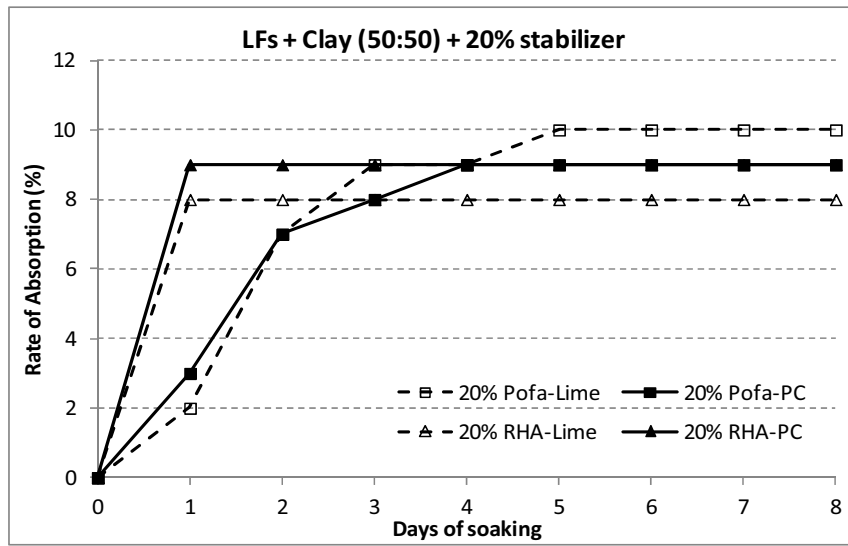

Figure 5: Rate of water absorption for Stabilized Landfill soil-Clay (50:50) with 20\% blended stabilizer

\section{Conclusion and Recommendation}

Based on the laboratory results obtained, it suggested there are potential for the use of agricultural waste POFA and RHA as blended binders for soil stabilization and partial replacement of cement or lime. The main focus for this research was on the engineering performance, as established using unconfined compressive strength and water absorption upon soaking. The following conclusions are drawn from this investigation:

(a) The composition of POFA: PC (50:50) and RHA: PC (50:50) at 20\% dosage recorded the highest compressive strength of stabilized soil when clay was incorporated with landfill soil at 50:50 ratios.

(b) However when landfill soil on its own were stabilized with all blended stabilizer, the strength recorded were half of the strength achieved when clay were incorporate in the system.

(c) The result shows that POFA and RHA are capable to replace certain amount of cement and lime in soil stabilization but not in a large scale. RHA are more favorable stabilizer in terms of strength development when combined with PC. The ratio of lime and PC must always be the dominant ingredient for stabilization.

(d) Incorporation of agricultural wastes POFA and RHA as stabilizer, tend to absorb high percentage of water compared to control specimen. This shows that although the addition of POFA or RHA assist to increase the compressive strength of stabilized soil but it has a lower durability compared to lime or PC stabilized soil. 


\section{Acknowledgement}

The authors would also like to thank Universiti Teknologi MARA, for the Research Intensive Faculty Fund (RIF), Project Code: 600-RMI/Dana 5/3/RIF (209/2012) for sponsoring this research.

\section{References}

1. Industrial Resource Council, 2012. Soil Stabilization.

http://www.industrialresourcescouncil.org/Applications/SoilStabilization/tabid/443/Default.aspx

2. Safiuddin, Jumaat, Salam, and Hafizan, 2010. Best Use of Palm Oil Fuel Ash. Retrieved on 20 April 2012 from

http://Theindependentbd.Com/Paper-Edition/Others/Freeforall/12019-Best-Use-Of-Palm-OilFuel-Ash.Html

3. Sumadi and Hussin, 1995. Palm Oil fuel Ash (POFA) as a Future Partial Cement Replacement Material, Housing Construction. Journal of Ferrocement. Vol.25 (1).

4. Pauzi, N. I., Omar, H., \& M. Yusoff, Z., 2011. Geotechnical Properties of Waste Soil from Open Dumping Area in Malaysia. Retrieved 12 2011, from www.ejge.com/2011/Ppr11.090/Ppr11.090alr.pdf.

5. Agamuthu and Khan, 1997. Effective Solid Waste Management In Malaysia. Ecotone Management Sdn Bhd

6. Hegde and Daware , 2010. Effect of Alternate Wetting and Drying on Laterite and Their Engineering Behaviour, Indian Geotechnical Conference, GEOtrendz December 16-18, IGS Mumbai Chapter \& IIT Bombay.

7. Eisazadeh, Khairul Anuar Kassim, Hadi Nur, 2012. Solid-state NMR and FTIR studies of lime stabilized montmorillonitic and lateritic clays. Applied Clay Science. Vol. 67-68, October 2012, Pages 5-10

8. Abdullah, Hussin, Zakaria, Muhamad, Hamid, 2006. POFA: A Potential Partial Cement Replacement Material in Aerated Concrete. Proceedings of the 6th Asia-Pacific Structural Engineering and Construction Conference (APSEC 2006), 5 - 6 September 2006, Kuala Lumpur, Malaysia

9. Sata, Jaturapitakkul, and Kiattikomol, 2004. Utilization of Palm Oil Fuel Ash in High Strength Concrete. Journal of Materials in Civil Engineering. ASCE (16) 623-628.

10. Galau, 2010. Characterization of Palm oil Fuel Ash from Different Mill as Cement Replacement Material. Bachelor Degree Dissertation, University Technology Malaysia (UTM). Malaysia. 